\title{
Analysis of change in relative uncertainty in GHG emissions from stationary sources for the EU 15
}

\author{
Myroslava Lesiv • Andriy Bun • Matthias Jonas
}

Received: 22 December 2012 / Accepted: 2 February 2014 /Published online: 27 February 2014

(C) The Author(s) 2014. This article is published with open access at Springerlink.com

\begin{abstract}
Total uncertainty in greenhouse gas (GHG) emissions changes over time due to "learning" and structural changes in GHG emissions. Understanding the uncertainty in GHG emissions over time is very important to better communicate uncertainty and to improve the setting of emission targets in the future. This is a diagnostic study divided into two parts. The first part analyses the historical change in the total uncertainty of $\mathrm{CO}_{2}$ emissions from stationary sources that the member states estimate annually in their national inventory reports. The second part presents examples of changes in total uncertainty due to structural changes in GHG emissions considering the GAINS (Greenhouse Gas and Air Pollution Interactions and Synergies) emissions scenarios that are consistent with the EU's "20-20-20" targets. The estimates of total uncertainty for the year 2020 are made under assumptions that relative uncertainties of GHG emissions by sector do not change in time, and with possible future uncertainty reductions for non- $\mathrm{CO}_{2}$ emissions, which are characterized by high relative uncertainty. This diagnostic exercise shows that a driving factor of change in total uncertainty is increased knowledge of inventory processes in the past and prospective future. However, for individual countries and longer periods, structural changes in emissions could significantly influence the total uncertainty in relative terms.
\end{abstract}

This article is part of a Special Issue on "Third International Workshop on Uncertainty in Greenhouse Gas Inventories" edited by Jean Ometto and Rostyslav Bun.

Electronic supplementary material The online version of this article (doi:10.1007/s10584-014-1075-6) contains supplementary material, which is available to authorized users.

M. Lesiv

Systems Research Institute, Polish Academy of Sciences, Newelska 6, 01-447 Warsaw, Poland

M. Lesiv $(\bowtie)$

Lviv Polytechnic National University, str. Bandera 12, PO Box 5446, Lviv 79031, Ukraine

e-mail: myroslava.lesiv@gmail.com

A. Bun

Delft University of Technology, Stevinweg 1, Postbus 5048, 2628 CN Delft, Netherlands

M. Jonas

International Institute for Applied Systems Analysis, Schlossplatz 1, 2361 Laxenburg, Austria 


\section{Introduction}

The increase in GHG concentrations during the last decades is considered to be the main reason for global warming. The Kyoto Protocol to the United Nations Framework Convention on Climate Change (UNFCC), whose term ended in 2012, stipulated the reporting of GHG emissions at national scale. The recent goal of the UNFCC is to establish post-Kyoto emission reductions targets for the period from 2012. Meantime, the European Union (EU-27), as a Party to the UNFCC, has set ambitious targets for the year 2020: the reduction of GHG emissions by $20 \%$ (or $30 \%$ - see below) by 2020 compared with 1990 levels (EEA 2010b).

Overall, EU-27 GHG emissions are decreasing. According to the inventory report (EEA 2010a), the EU-27 is well on track to achieve its emission reduction target of $20 \%$. This overall trend is projected to continue until 2020 . However, the $20 \%$ reduction target compared to 1990 would therefore remain out of reach without the implementation of additional measures, such as the EU's energy and climate change package (EC 2008). This package underlines the objectives of limiting the rise in global average temperature to no more than $2{ }^{\circ} \mathrm{C}$ above preindustrial levels (EC 2009). So, the Member States agreed to cut GHG emissions by at least $20 \%$ of 1990 levels (30\% if other developed countries commit to comparable cuts), which equals a $14 \%$ reduction compared with 2005 levels; to cut energy consumption by $20 \%$ of projected 2020 levels by improving energy efficiency; and to increase the use of renewables (wind, solar, biomass, etc.) to $20 \%$ of total final energy consumption.

Uncertainty in GHG emissions is a crucial component of inventories. It specifies the absence of confidence in the inventory inputs as a result of casual factors, such as uncertainty of emission sources and emission factors, absence of transparency in the inventory process (IPCC 2006; API/CONCAWE/IPIECA 2009), and so on. In compliance with international obligations, countries should have guarantees that reported GHG emissions are sufficiently accurate. Up to now, GHG emissions and the corresponding uncertainties are still reported separately and are not considered in carbon emission trading (Ermolieva et al. 2010).

The application of a number of existing techniques to analyze emissions and emission changes against their uncertainty could provide useful knowledge that countries would like to have available prior to agreeing to emission targets (Jonas et al. 2004, 2010a, b; Bun et al. 2010). At the same time, countries should strive to provide more accurate results regarding GHG emissions. In order to decrease the level of uncertainty, the knowledge of inventory processes has to be expanded and the key reasons and emission sources that determine the level of uncertainty have to be identified.

Experience in assessing the uncertainty in GHG inventories and changes in uncertainty in relative terms is still insufficient (Lieberman et al. 2007; Jonas et al. 2010a, b; NRC 2010). So far, no studies have been done on the analysis of changes in uncertainties that countries reported in their national inventory reports. For example, from year to year countries report different values of relative uncertainties in total GHG emissions. What is the main reason for changes in reported uncertainties: structural changes in emissions or increased knowledge about inventory processes? How will uncertainties change in the future due to structural changes in GHG emissions under new policy treaties (e.g., the EU's 2020 targets)? Answers to these questions will help to better communicate the uncertainty and can be used to improve the setting of emission targets in the future.

Here, we conducted an analysis of the changes in uncertainty in relative terms in the past and nearby future for European countries. The input data (uncertainties by source) were derived from national inventory reports (NIR 2003-2008), and emissions scenarios were taken from the Greenhouse Gas and Air Pollution Interactions and Synergies (GAINS) model (IIASA 2010). 
Our study is divided into two parts: (1) diagnostic analysis of the historical change in uncertainty, particularly the influence of structural changes in emissions; (2) a diagnostic exercise with one step forward: we calculate the total uncertainty with which we will have to cope at a specified point in time in the future using today's diagnostic capabilities. The paper presents an analysis of the historical change in uncertainty of $\mathrm{CO}_{2}$ emissions for the EU-15 as a whole and for individual countries; and it also includes estimates of total uncertainty in GHG emissions under scenarios of changes in emissions considering the EU's "20-20-20" targets.

\section{Methodological background}

Parties to the UNFCCC publish their GHG inventory reports annually in consistency with standardized guidelines for national agencies developed by the Intergovernmental Panel on Climate Change (IPCC 1997, 2006). Parties are obliged to include in their reports direct or alternative estimates of uncertainty in results of GHG inventories. The quality of reported uncertainty varies significantly from country to country because countries do not use the same method for their emission and uncertainty assessments. The estimates of $\mathrm{CO}_{2}$ emissions from fossil fuels consumption are the most accurate for comparison with other source categories (uncertainties are estimated in the range of $\pm 5 \%$ ) (Marland et al. 2008).

The EU member states started to report their uncertainties in GHG emissions in different years. The first estimates of relative uncertainty were added to GHG inventory reports in 2000 and they did not cover all source categories and gases. In contrast, GHG emissions were calculated much earlier. The ranges of total uncertainty of GHG emissions for the EU-15 are available from the year 2003; the uncertainty of $\mathrm{CO}_{2}$ emissions from fossil fuel combustion (stationary) has been detailed by source only since 2005 .

Total uncertainty changes over time due to increased knowledge of inventorying GHGs and structural changes in emission sources (and sinks). The first estimates of changes in uncertainties in the past were provided in the Interim Report (Hamal 2010). The reported uncertainties in the national inventory reports reflect precision and do not consider accuracy. Precision expresses the degree of reproducibility of repeated emissions (random errors). Accuracy is the difference between the reported emissions estimate and the actual value (systematic errors). Hamal (2010) calculated combined relative uncertainties (for the EU15), which consider accuracy and precision, using knowledge of emissions recalculations to estimate biases (systematic errors). The results, fitted with a trend function that follows an exponential curve with a decrease of approximately $4.24 \%$ each year, are displayed in Fig. 1.

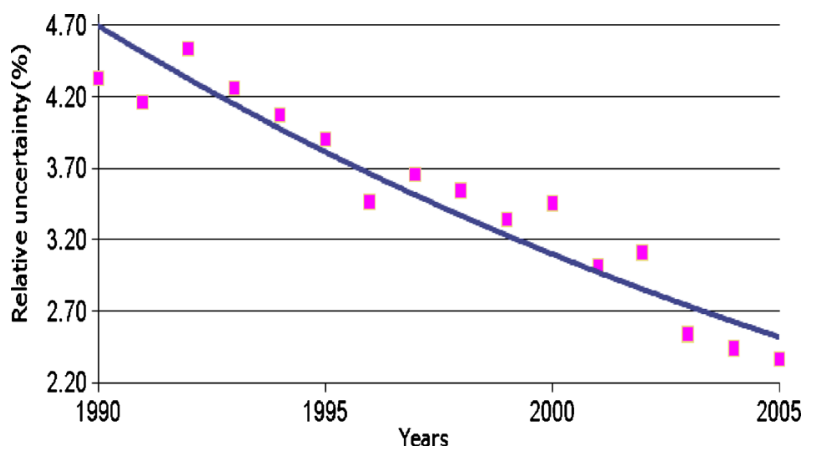

Fig. 1 Total uncertainty ranges fitted with exponential trend function (Source: Hamal 2010) 
This change in uncertainty is expected to be more significant for the LULUCF (Land Use, Land-Use Change and Forestry) sector and for other GHGs that are less certain.

The decrease (Fig. 1) in the past is believed to be almost exclusively caused by "learning" and only marginally by structural changes in fossil fuel consumption. "Learning" means the process of increasing knowledge of emission factors, other parameters, and activity data and improving the inventory methods and models. However, some structural changes in emissions as the result of implementing new energy measures can cause more significant decreases or even increases in uncertainty. This happens because the uncertainty of emissions from different fuels is not the same (i.e., combustion of liquid and other fuels involves a bigger uncertainty than that of solid and gaseous fuels).

Structural changes in emissions occur all the time; for example the structure of fossil fuels consumption changes, and each fuel has a different emission factor. Replacing consumption of one fuel by another could result in an increase or decrease in the total uncertainty.

In the next two chapters, we present the methodology used to analyse historical changes in relative uncertainty and future estimates of uncertainty in GHG emissions from stationary sources. Table 1 includes a description of data sources used in the study.

\subsection{Historical change in uncertainty of $\mathrm{CO}_{2}$ emissions}

We have analyzed the change in total uncertainty of $\mathrm{CO}_{2}$ emissions by the following steps:

1. Collecting data on GHG emissions and their uncertainties by source categories (Table 1).

2. Calculation of the contribution of uncertainties in total emissions (fraction, \%) at the beginning and end of the investigated period:

$$
\widetilde{U}_{i}=\frac{x_{i}}{\sum_{j=1}^{n} x_{j}} \cdot U_{i} \quad \text { or } \quad \widetilde{U}_{i}=r_{i} \cdot U_{i},
$$

where $\widetilde{U}_{i}$ is the combined uncertainty in category $i$ as a proportion of total emissions (\%); $U_{i}$ is the relative uncertainty of emissions in category $i, i=1 . . n$ (see Table 1 ) (\%); $x_{i}$ is the uncertain quantity (emissions) of category $i$ (see Table 1 ); $r_{i}=x_{i} / \sum_{j=1}^{n} x_{j}$ is the fraction of source category $i$ in total emissions.

Formula (1) follows from Approach 1 described in Chapter 3 of the IPCC Guidelines (IPCC 2006).

Table 1 Data description

Data $\quad$ Source

1. Historical change in total uncertainty of $\mathrm{CO}_{2}$ emissions

$\mathrm{CO}_{2}$ emissions of fossil fuels consumption by category $\left(x_{i}\right)$

Relative uncertainty by gas and category $\left(U_{i}\right)$

2. Future change in total uncertainty

GHG emissions in $\mathrm{CO}_{2}$ equivalent by sectors

Relative uncertainty by gas and sector
National Inventory Reports (2000-2010) for the Member States (Germany, the United Kingdom, Italy, France, Spain, the Netherlands, Belgium, Greece, Austria, Portugal, Finland, Ireland, Sweden, Denmark) (UNFCCC 2010);

Annual European Inventory Reports to the UNFCC (EEA 2003-2010)

Annual European Inventory Reports to the UNFCC (2003-2010) 
3. Analysis of the change in uncertainty due to increased knowledge: We consider that if uncertainty of elementary category $\left(U_{i}\right)$ changes during the investigated period it changes due to the learning process, for example increased knowledge on uncertainty of emission factors or activity data, while the structural change $\left(r_{i}\right)$ always occurs; for shorter periods it is negligible but for longer ones it could be very significant.

4. If the change in uncertainty occurs in category $i$ due to increased knowledge, we use elements from deterministic factor analysis theory to compare the influence of the structural change in emissions and the "learning" on this change:

$$
\begin{gathered}
\Delta \widetilde{U}_{i}=\Delta \widetilde{U}_{i, r}+\Delta \widetilde{U}_{i, U}, \\
\Delta \widetilde{U}_{i, r}=\Delta \widetilde{U}_{i} \cdot \ln \left(\frac{r_{i}^{1}}{r_{i}^{0}}\right) / \ln \left(\frac{\widetilde{U}_{i}^{1}}{\widetilde{U}_{i}^{0}}\right), \Delta \widetilde{U}_{i, U}=\Delta \widetilde{U}_{i} \cdot \ln \left(\frac{U_{i}^{1}}{U_{i}^{0}}\right) / \ln \left(\frac{\widetilde{U}_{i}^{1}}{\widetilde{U}_{i}^{0}}\right),
\end{gathered}
$$

where $\Delta \widetilde{U}_{i, r}$ is the absolute change in relative uncertainty due to the structural change in emissions (\%), $\Delta \widetilde{U}_{i, U}$ is the absolute change in relative uncertainty due to "learning" in source category $i(\%)$; super-indices 1 and 0 mean the end and the beginning of the investigated period, respectively.

If the change in uncertainty occurs in category $i$ only due to the structural change in emissions, we go to the next step.

5. Analysis of change in relative uncertainty of $\mathrm{CO}_{2}$ emissions for every source category and for the sector as whole.

A detailed example of uncertainty analysis of $\mathrm{CO}_{2}$ emissions (stationary sources) by the steps described above is presented in Table 2, where the calculations are made for Finland, as it is one of the first countries that started to report uncertainties in GHG emissions in 2000. During the investigated period (2000-2008), knowledge of the inventory processes in some categories increased, and structural changes in fossil fuel consumption also occurred.

\subsection{Future changes in uncertainty}

Using today's diagnostic capabilities we are able to measure and distinguish between "learning" and structural change in the past and also in the future. We would call this "a diagnostic

Table 2 The analysis of the relative uncertainty of $\mathrm{CO}_{2}$ emissions (stationary sources) without LULUCF for

\begin{tabular}{|c|c|c|c|c|c|c|c|}
\hline \multirow[t]{2}{*}{ Fossil fuel } & \multicolumn{2}{|c|}{$\begin{array}{l}\text { Fraction of } \mathrm{CO}_{2} \\
\text { emissions (stationary), } r_{i}\end{array}$} & \multicolumn{2}{|c|}{$\begin{array}{l}\text { Reported relative } \\
\text { uncertainty, } U_{i}, \%\end{array}$} & \multicolumn{2}{|c|}{$\begin{array}{l}\text { Uncertainty as a proportion of } \\
\text { total } \mathrm{CO}_{2} \text { emissions (stationary), } \%\end{array}$} & \multirow[t]{2}{*}{$\Delta \widetilde{U}_{i, U}, \%$} \\
\hline & 2000 & 2008 & 2000 & 2008 & 2000 & 2008 & \\
\hline Natural gas & 0.14 & 0.15 & 1.41 & 1.41 & 0.20 & 0.22 & 0 \\
\hline Oil & 0.43 & 0.45 & 2.83 & 2.83 & 1.22 & 1.28 & 0 \\
\hline Solid fuels & 0.28 & 0.23 & 3.35 & 10.13 & 0.93 & 2.31 & 1.68 \\
\hline Other fuels & 0.15 & 0.17 & 6.40 & 6.59 & 0.97 & 1.09 & 0.03 \\
\hline Total & 1 & 1 & & & 1.83 & 2.86 & \\
\hline \multicolumn{7}{|c|}{ Absolute change in relative uncertainty in $2000-2008$ : } & $1.03 \%$ \\
\hline
\end{tabular}
Finland (2000-2008)

The main reason for the increase in uncertainty is "learning" processes (inventory of emissions from solid fuels combustion) 
exercise with one step forward". We estimate the total uncertainty by combining uncertainties in GHG emissions from different sectors. Our main assumption is that our future knowledge of uncertainty in activity data and carbon content will be the same as today's knowledge in relative terms. So, relative uncertainty is kept constant in both activity data and carbon content during the investigated period.

To combine uncertainties, the Tier 1 approach described in Chapter 3 of the IPCC Guidelines (IPCC 2006) is used:

- Uncertainty in the results of multiplication of uncertain values is computed as:

$$
U_{\text {total }}=\sqrt{U_{1}^{2}+U_{2}^{2}+\cdots+U_{n}^{2}},
$$

where $U_{\text {total }}$ is the combined uncertainty in relative terms; $U_{i}$ is relative uncertainty in value $i$.

- Uncertainty in the results of addition and subtraction:

$$
U_{\text {total }}=\frac{\sqrt{\left(U_{1} \cdot x_{1}\right)^{2}+\left(U_{2} \cdot x_{2}\right)^{2}+\ldots+\left(U_{\mathrm{n}} \cdot x_{n}\right)^{2}}}{\left|x_{1}+x_{2}+\ldots+x_{n}\right|},
$$

where $x_{i}$ is uncertain quantity $i$.

While implementing Formulas (4) and (5), correlation between years is not considered, as we estimate the total uncertainty at one point in time.

The GHG inventory is principally the sum of products of emission factors, activity data, and other estimation parameters. Therefore, Approach 1 can be implemented repeatedly to estimate the uncertainty of the total inventory. We use Formula (4) to combine uncertainties in activity data and emission factor, and Formula (5) to combine uncertainties from fossil fuels consumption.

\section{Results and discussion}

Fossil fuel consumption is the most precise and the main key source of GHG emissions. The relative uncertainty of GHG emissions from fossil fuel burning is still considerable (up to $10 \%$ ) and influences the results of GHG inventories. The main causes of uncertainty are uncertainties in emission factors, activity data, and methods used (so far, UNFCC methods are the most reasonable). Other sectors' emission sources, such as industrial processes, agriculture, forestry and other land uses, and waste, cause lower emissions of certain kinds. For some countries, the uncertainties in GHG emissions in these categories can be less than $25 \%$ or more than $100 \%$ (NRC 2010) due to the insufficient accuracy of input data and models. Sectors other than energy are not key emission sources but might be key uncertainty sources of total uncertainty of GHG inventories because of the large size of the uncertainties. Our analysis is focused mainly on the uncertainty of fossil fuel $\mathrm{CO}_{2}$ emissions as it is the key source of GHG emissions in EU countries and the main object of international climate agreements and emission trading.

\subsection{Historical change in uncertainty of $\mathrm{CO}_{2}$ emissions}

To date only a few studies have analysed the change in relative uncertainties in GHG emissions due to structural changes in emissions and "learning" (Hamal 2010; Lesiv 2012). Here, the 
uncertainty analysis has been carried out for the EU-15 as a whole and for individual countries. The reported uncertainty for the EU-15 covers a short period only, which is not sufficient to carry out a proper analysis of the change in uncertainty and the factors influencing total uncertainty in relative terms. During the period 2003-2008 the emission structure did not change significantly, so the main reason for the change in uncertainty is the so-called "learning process". For such a short period it is impossible to find any tendency of the change in uncertainty.

Further research focuses on the country level because data on uncertainties of $\mathrm{CO}_{2}$ emissions (stationary sources) are available for a longer period for individual countries. The analysis was carried out for the 15 member states.

One of the biggest GHG emitters is Germany, whose share of total emissions of the EU-15 is about $30 \%$. The reported uncertainty of $\mathrm{CO}_{2}$ emissions decreased by $13 \%$ during the period 2003-2008. During that period the structure of uncertainty estimates changed several times. The results of uncertainty analysis are shown in Table 3 . The decrease in uncertainty is caused mainly by increased knowledge of the inventory processes in category "1.A.2. Manufacturing Industries and Construction".

Table 4 represents the results of analysis of the change in historical uncertainty of $\mathrm{CO} 2$ emissions (stationary sources) without LULUCF for Germany for the period 1990-2008 under the assumption that the relative uncertainty by category in 1990 is equal to the first estimates of uncertainty reported in 2003. During this period there were significant structural changes in fossil fuel consumption: a decrease in use of solid fuels and an increase in use of gaseous fuels. Mainly the decreasing solid fuels consumption in the category "1.A.2. Manufacturing industries and construction" reflected the decrease in total uncertainty. The ranges of total uncertainty during 1990-2008 were reduced by approximately $16 \%$ (considering only precision).

The results of the uncertainty analysis for the EU-15 Member States are summarized in Table 5, except for Luxemburg, which first reported the uncertainty of GHG emissions in

Table 3 The analysis of relative uncertainty of $\mathrm{CO}_{2}$ emissions (stationary sources) without LULUCF for Germany (2003-2008)

\begin{tabular}{|c|c|c|c|c|c|}
\hline \multirow[t]{2}{*}{ Category } & \multicolumn{2}{|c|}{$\begin{array}{l}\text { Fraction } \\
\text { of } \mathrm{CO}_{2} \\
\text { emissions } \\
\text { (stationary), } r_{i}\end{array}$} & \multicolumn{2}{|c|}{$\begin{array}{l}\text { The square } \\
\text { of combined } \\
\text { uncertainty as } \\
\text { a percentage of } \\
\mathrm{CO}_{2} \text { emissions } \\
\text { (stationary), } \widetilde{U}_{i}^{2} \%\end{array}$} & \multirow[t]{2}{*}{ Analysis } \\
\hline & 2003 & 2008 & 2003 & 2008 & \\
\hline $\begin{array}{l}\text { 1.A.1.a Public electricity } \\
\text { and heat production }\end{array}$ & 0.480 & 0.530 & 0.064 & 0.057 & $\begin{array}{l}\text { Change is caused by structural } \\
\text { change in emissions and "learning" }\end{array}$ \\
\hline 1.A.1.b Petroleum refining & 0.029 & 0.036 & 0.000 & 0.000 & Negligible change \\
\hline 1.A.1.c Manufacture of solid fuels & 0.031 & 0.022 & 0.000 & 0.000 & Negligible change \\
\hline $\begin{array}{l}\text { 1.A.2. Manufacturing industries } \\
\text { and construction }\end{array}$ & 0.192 & 0.158 & 0.020 & 0.002 & $\begin{array}{l}\text { Significant change caused by } \\
\text { "learning" and to a lesser } \\
\text { extent by structural change }\end{array}$ \\
\hline 1.A.4.a Commercial/institutional & 0.073 & 0.067 & 0.003 & 0.003 & Negligible change \\
\hline 1.A.4.b Residential & 0.182 & 0.174 & 0.019 & 0.020 & Negligible change \\
\hline 1.A.4.c Agriculture/forestry/fisheries & 0.010 & 0.011 & 0.000 & 0.000 & Negligible change \\
\hline 1.A.5. Others & 0.003 & 0.002 & 0.000 & 0.000 & Negligible change \\
\hline
\end{tabular}


Table 4 The analysis of relative uncertainty of $\mathrm{CO}_{2}$ emissions (stationary sources) without LULUCF for Germany (2000-2008)

\begin{tabular}{|c|c|c|c|c|c|}
\hline \multirow[t]{2}{*}{ Category } & \multicolumn{2}{|c|}{$\begin{array}{l}\text { Fraction of } \\
\mathrm{CO}_{2} \text { emissions } \\
\text { (stationary), } r_{i}\end{array}$} & \multicolumn{2}{|c|}{$\begin{array}{l}\text { The square of combined } \\
\text { uncertainty as a part } \\
\text { of } \mathrm{CO}_{2} \text { emissions } \\
\text { (stationary), } \widetilde{U}_{i}^{2} \%\end{array}$} & \multirow[t]{2}{*}{ Analysis } \\
\hline & 1990 & 2008 & 1990 & 2008 & \\
\hline $\begin{array}{l}\text { 1.A.1.a Public electricity } \\
\text { and heat production }\end{array}$ & 0.405 & 0.530 & 0.047 & 0.057 & $\begin{array}{l}\text { Change is caused by structural } \\
\text { change in emissions } \\
\text { and "learning" }\end{array}$ \\
\hline 1.A.1.b Petroleum refining & 0.023 & 0.036 & 0.000 & 0.000 & Negligible change \\
\hline $\begin{array}{l}\text { 1.A.1.c Manufacture of } \\
\text { solid fuels }\end{array}$ & 0.072 & 0.022 & 0.002 & 0.000 & Negligible change \\
\hline $\begin{array}{l}\text { 1.A.2. Manufacturing industries } \\
\text { and construction }\end{array}$ & 0.238 & 0.158 & 0.044 & 0.002 & $\begin{array}{l}\text { Significant change caused by } \\
\text { the structural change and } \\
\text { less by "learning" }\end{array}$ \\
\hline 1.A.4.a Commercial/institutional & 0.075 & 0.067 & 0.003 & 0.003 & Negligible change \\
\hline 1.A.4.b Residential & 0.156 & 0.174 & 0.019 & 0.020 & Negligible change \\
\hline $\begin{array}{l}\text { 1.A.4.c Agriculture/forestry/ } \\
\text { fisheries }\end{array}$ & 0.016 & 0.011 & 0.000 & 0.000 & Negligible change \\
\hline 1.A.5. Others & 0.014 & 0.002 & 0.000 & 0.000 & Negligible change \\
\hline
\end{tabular}

2007. Countries are sorted by emitters starting from the largest, that is, Germany, because of its larger contribution to the total emissions and uncertainty of the EU-15. The last column of Table 5, "Analysis of the influence of individual factors on the change in uncertainty" includes the "decrease" or "increase" in uncertainty and the main cause of its change.

Structural change in emissions always occurs and over longer periods it could significantly influence the total uncertainty in relative terms. The analysis of the historical change in total uncertainty of $\mathrm{CO}_{2}$ emissions (stationary sources) shows that for individual countries the structural change in emissions may be the main factor in the uncertainty change while for the EU-15 total uncertainty varies mainly due to the increased knowledge on inventory processes ("learning"). For example, for Italy, France, the Netherlands, Belgium, Greece, and Denmark, changes in uncertainty of $\mathrm{CO}_{2}$ emissions are caused mainly by structural changes in emissions; in contrast, for Germany, the UK, Austria, Portugal, Finland, and Sweden, they are caused mainly by "learning" (the change in estimates of emission factors and activity data).

\subsection{Future change in uncertainty of total GHG emissions}

Based on the above past analysis and considering the EU's ambitious targets under the Integrated Energy and Climate Change package, more structural changes in fuel consumption are expected in the future. The estimation of relative uncertainty in GHG emissions for a certain point of time in the future would show whether uncertainty in total inventory results will increase or decrease and would identify the main reason for changes in uncertainty.

Further, the results of uncertainty estimates for the year 2020 are described. As mentioned in Section 2.2, we assume that our future knowledge of uncertainty in activity data and carbon content will be the same as today's knowledge in relative terms. In other words, relative uncertainty is kept constant during the investigated period. For our calculations we took emission scenarios developed at the International Institute for Applied Systems Analysis 


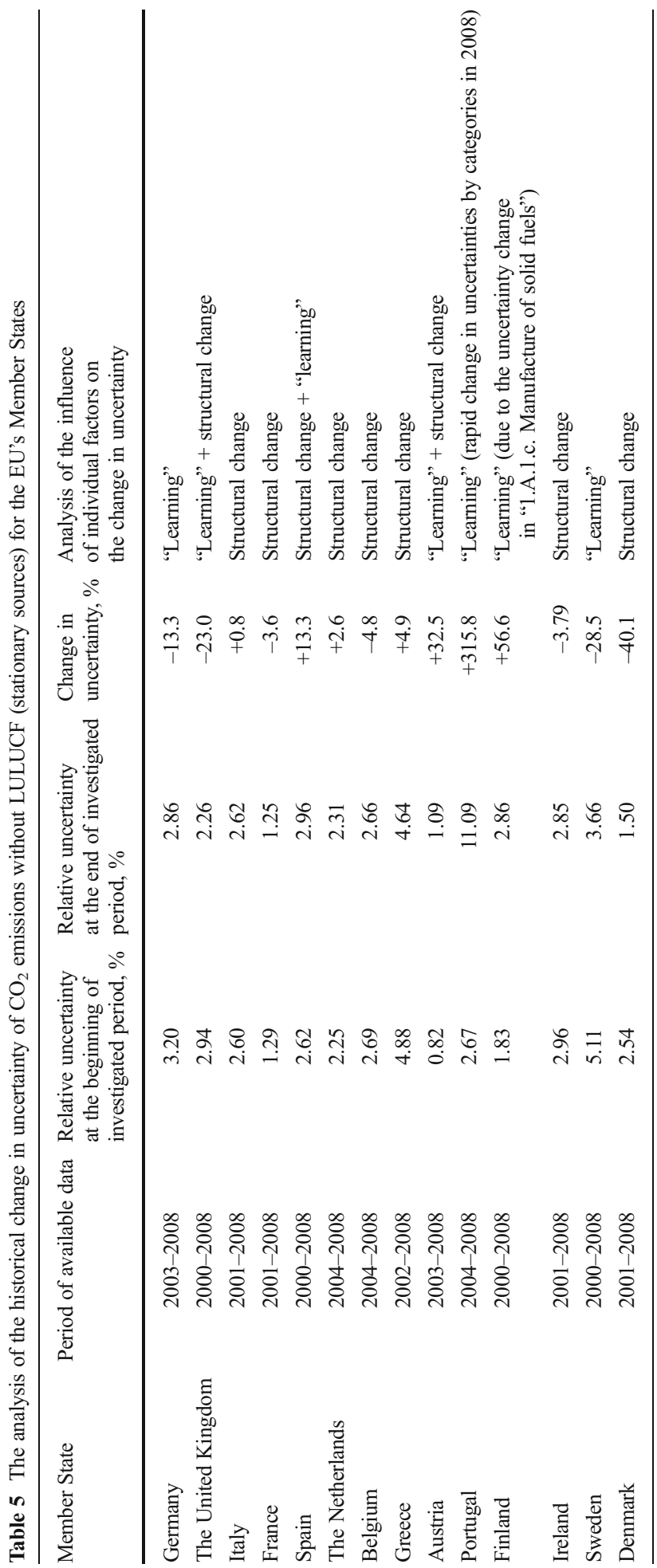


(GAINS) because they are based on countries' emission projections and reflect the results of implementing new policies and measures and also a baseline scenario. More information on the above scenarios is available on the GAINS website (IIASA 2010).

The calculations were based on the GAINS emission scenarios for the EU-15 for the year 2020 (see Box 1).

The results of calculation of the total uncertainty are shown in Fig. 2. "C\&E package + NitrDir; OPTV5" is the only scenario that results in a decrease in total uncertainty in relative terms due to the structural change, because it assumes an appreciable emission reduction in the agricultural sector, which is characterized by high uncertainties.

Assessments of total uncertainty in relative terms were also made while considering possible reductions in uncertainties of GHG emissions in fugitive emissions and the agricultural and waste sectors, which could be achieved in the future (2020). We assumed that the uncertainty of fugitive emissions will decrease to $25 \%$, that of GHG emissions in agriculture to $50 \%$, and that of GHG emissions from waste to $15 \%$. These assumptions were based on given possible improvements in uncertainty assessment in a few years for developed countries (NRC 2010). The results are illustrated in Fig. 3.

Figure 3 shows that reductions in uncertainties in fugitive emissions, agriculture, and waste can cause a significant decrease in total uncertainty in relative terms. Even in the case of the "worst" emission scenario, "C\&E package; current legislation", which does not consider implementation of new policies legislatively, the total uncertainty decreases over time. Comparison of the results achieved (Figs. 2 and 3) shows that "learning" is a driving factor of decreases in total uncertainty in relative terms.

The conducted analysis is based on reported uncertainties in relative terms that consider only precision. The recalculations of total uncertainty considering accuracy increase uncertainty ranges and reinforce the influence of increased knowledge on inventory processes (Hamal 2010).

C\&E package; current legislation

C\&E package;current policy

PRIMES_2009

C\&E package+NoRen; OPTV5

C\&E package; least-cost of CLE

C\&E package+IMO light; OPTV5

C\&E package+PrimPM2.5; OPTV5

C\&E package; MRRV5

C\&E package; OPTV5

C\&E package; EP targets; OPTV5

NEC2007 baseline; current policy

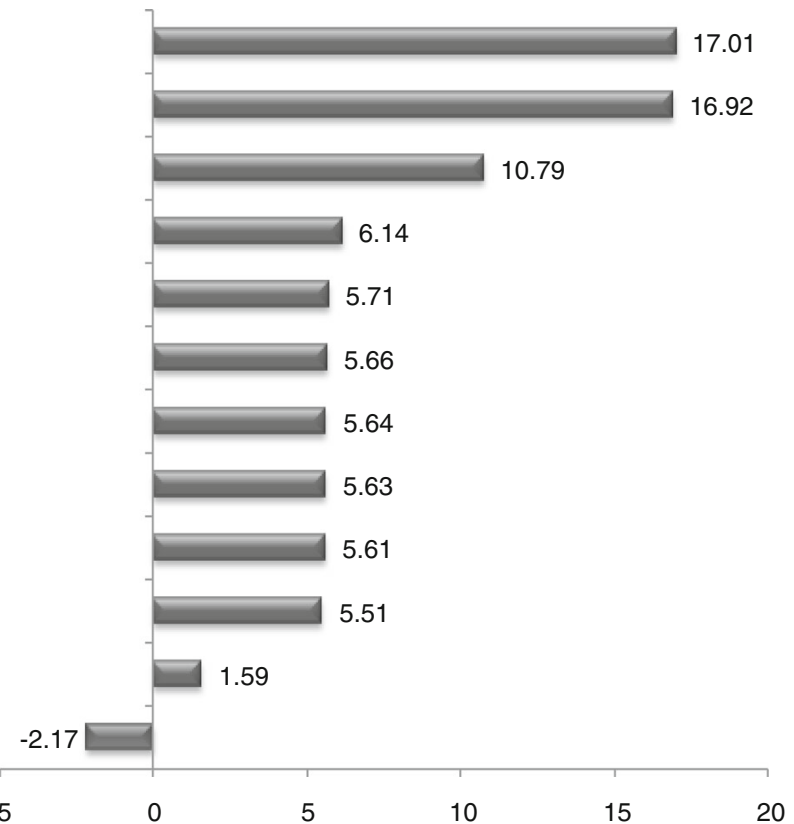

C\&E package+NitrDir; OPTV5

Fig. 2 Change (\%) in total uncertainty of GHG emissions for EU-15 in 2020 under GAINS emissions scenarios (without LULUCF) 
C\&E package; current legislation

C\&E package;current policy

PRIMES_2009

$-16.71$

C\&E package+NoRen; OPTV5

C\&E package; least-cost of CLE

C\&E package+IMO light; OPTV5

C\&E package+PrimPM2.5; OPTV5

C\&E package; MRRV5

C\&E package; OPTV5

C\&E package; EP targets; OPTV5

NEC2007 baseline; current policy

C\&E package+NitrDir; OPTV5

\section{$-20.35$}

$-20.61$

$-20.65$

$-20.66$

$-20.68$

$-20.69$

$-20.76$

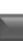
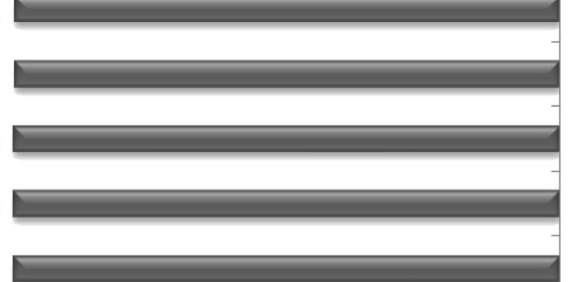

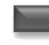

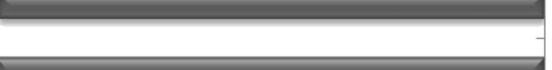

$-23.38$

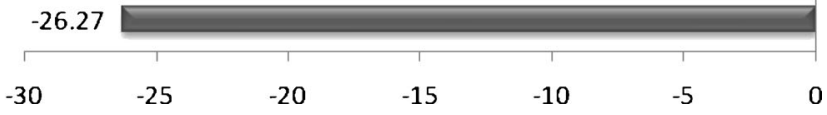

Fig. 3 Reduction (\%) in total uncertainty of GHG emissions for the EU-15 in 2020 under GAINS emissions scenarios considering possible increases in knowledge in sectors with high uncertainty (without LULUCF)

The estimates of uncertainty in $\mathrm{CO}_{2}$ emissions from stationary sources are the most certain and can be improved more because not all countries use higher tier inventory methods and emission factors or other estimation parameters and their associated uncertainties, which should be estimated from original research including country-specific data.

In terms of global carbon accounting, the sizes of changes in uncertainties are not that large. However, at country level these changes in uncertainties over time should be considered while establishing new international agreements on GHG emission targets. Also, decreased uncertainties in GHG emissions will make emissions trading between countries clearer.

Box 1. GAINS emission scenarios

C\&E (Climate \& Energy) package + NitrDir; OPTV $5^{1}$ — an optimized emission scenario that assumes an energy projection that is consistent with the EU's "20-20-20" targets; and an agricultural projection that explores the potential implications of a full implementation of the Nitrates Directive (EC 1991);

NEC2007 baseline; current policy - an emission scenario that employs the PRIMES baseline projection of November 2007, which illustrates a business-as-usual case without further climate measures, and an agricultural projection that reflects national perspectives on the development of the agricultural sector;

$C \& E$ package; EP targets; OPTV 5 - an optimized emission scenario that assumes an energy projection that is consistent with the EU's "20-20-20" targets, and an agricultural projection that reflects national perspectives on the development of the agricultural sector; it meets more stringent environmental objectives in 2020, as requested by the European Parliament;

C\&E package; OPTV 5 - an optimized emission scenario that assumes an energy projection that is consistent with the EU's "20-20-20" targets, and an agricultural projection that reflects national perspectives on the development of the agricultural sector;

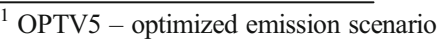


$C \& E$ package; $M R R V 5^{2}$ is based on the activity projections of the EU's " $20-20-20$ " targets and estimates the potential for further emission reductions that are achievable through a full application of the most advanced technical (add-on) emission control measures that are on the market today;

C\&E package + PrimPM2.5; OPTV5 - an optimized emission scenario that assumes an energy projection that is consistent with the EU's "20-20-20" targets and an agricultural projection that reflects national perspectives on the development of the agricultural sector and that health impacts of particulate matter are solely caused by primary emissions of PM2.5; that is, that secondary aerosols would not cause negative health effects;

$C \& E$ package + IMO light; OPTV5 - an optimized emission scenario that assumes an energy projection that is consistent with the EU's "20-20-20" targets and an agricultural projection that reflects national perspectives on the development of the agricultural sector and the new limits for emissions that were agreed at a meeting of the International Maritime Organisation (IMO) Marine Environment Protection Committee (MEPC) in April 2008;

$C \& E$ package; least-cost of CLE presents the least-cost implementation of the emission levels of the current policy case of the EU's "20-20-20" strategy;

$C \& E$ package + NoRen; OPTV5 - an optimized emission scenario that assumes an energy projection that is consistent with the EU's "20-20-20" targets (the $20 \%$ renewable target is met in this scenario within each country without international trading) and an agricultural projection that reflects national perspectives on the development of the agricultural sector;

PRIMES_2009_PRIMES baseline scenario of the year 2009;

$C \& E$ package; current policy assumes baseline for NECD plus the EU's "20-20-20" strategy;

$C \& E$ package; current legislation2014the "current legislation" projection for the Climate and Energy Package.

\section{Conclusions}

Total uncertainty in relative terms changes over time due to structural changes in GHG emissions and the increased knowledge of inventory processes or so-called "learning". Analysis of the historical change in uncertainty has been carried out for the EU-15 as well as for individual countries. The achieved results confirm that the uncertainty of $\mathrm{CO}_{2}$ emissions of the EU-15 has changed historically mainly due to increased knowledge of GHG inventory processes. In contrast, for some individual countries (Italy, France, Netherlands, Belgium, Greece, Denmark) total uncertainty of $\mathrm{CO}_{2}$ emissions (excluding LULUCF) changed in the past only due to structural changes in emissions. Germany, as the biggest European GHG emitter, reported a considerable decrease in uncertainty caused by "learning". The recalculations of total uncertainty considering accuracy lessen the influence of the structural change in emissions.

The calculations of total uncertainty in relative terms considering today's knowledge of inventory processes have been based on the GAINS emission scenarios until 2020. The estimates of total uncertainty that assume constant relative uncertainty during the investigated period show the increase in uncertainty for most of the emission scenarios except the scenario "C\&E package + NitrDir; OPTV5", which is consistent with the EU's "20-20-20" targets and an agricultural projection that explores the potential implications of a full implementation of the Nitrates Directive. Such an increase in total uncertainty is caused by the increased proportion of renewables, which have less certain emission factors and activity data, and decreased proportion of emission categories (agriculture, waste, etc.) in energy consumption. These changes in uncertainty due to structural change in emissions are negligible, though, while the estimates of total uncertainty of GHG emissions that assume a possible decrease in uncertainty in future due to the "learning" based on the GAINS emissions scenarios show a considerable decrease in total uncertainty. Thus improving our knowledge of fugitive

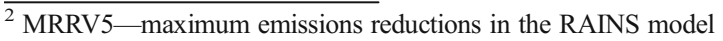


emissions and the agricultural and waste sectors could cause significant reductions in total GHG emissions uncertainties.

This study underlines that "learning" is the main reason for the change in uncertainty in the last few decades and could be a very important factor in uncertainty reduction in the near future. Scientists and experts should put more effort into increasing knowledge of the inventory processes, especially in sectors (agriculture, waste, etc.) which are expected to be the main drivers of uncertainties in GHG emissions.

Acknowledgments This research was funded by the Marie Curie Project No. 247645, entitled: GESAPUGeoinformation Technologies, Spatio-Temporal Approaches, and Full Carbon Account For Improving Accuracy of GHG Inventories, and the project "International $\mathrm{PhD}$ studies in Intelligent computing" financed with the European regional development fund, and the project of the Ministry of Education and Science of Ukraine. We thank the anonymous reviewers for their comments, which helped to improve the paper.

Open Access This article is distributed under the terms of the Creative Commons Attribution License which permits any use, distribution, and reproduction in any medium, provided the original author(s) and the source are credited.

\section{References}

API, CONCAWE, IPIECA (2009) Addressing uncertainty in oil and natural gas industry greenhouse gas inventories: technical considerations and calculation method. Pilot Version, London. Available at: http:// www.api.org/ehs/climate/response/upload/Addressing_Uncertainty.pdf

Bun A, Hamal K, Jonas M, Lesiv M (2010) Verification of compliance with GHG emissions target: annex B countries. Clim Chang 103:215-225

EC (1991) Nitrates Directive. Available at: http://ec.europa.eu/environment/water/water-nitrates/index en.html

EC (2008) Second strategic review - An EU security and solidarity action plan - Europe's current and future energy position - Demand - resources - investments. SEC (2008) 2871, Brussels, 13 November 2008 . Vol. 1. Available at: http://ec.europa.eu/energy/strategies/2008/2008_11_ser2_en.htm

EC (2009) EU action against climate change - Leading global action to 2020 and beyond. Directorate-General for the Environment Information Centre (BU-9 0/11), B-1049 Brussels

EEA (2003-2010) Annual European Union greenhouse gas inventories and inventory reports. Available at: http://www.eea.europa.eu/publications/\#c9=all\&c14=technical_report_2002_75\&c12=\&c7=en\&c11=5\&b_ start $=0$

EEA (2010) Annual European Union greenhouse gas inventory 1990-2008 and inventory report 2010. Available at: http://www.eea.europa.eu/publications/european-union-greenhouse-gas-inventory-2010

EEA (2010) Tracking progress towards Kyoto and 2020 targets in Europe. Denmark. Available at: http://www. eea.europa.eu/publications/progress-towards-kyoto.

Ermolieva T, Ermoliev Y, Fischer G, Jonas M, Makowski M, Wagner F (2010) Carbon emission trading and carbon taxes under uncertainties. Clim Chang 103(1):277-289

Hamal K (2010) Reporting greenhouse gas emissions: change in uncertainty and its relevance for the detection of emission changes. Interim report IR-10-003, Laxenburg, Austria: International Institute for Applied Systems Analysis. Available at: http://www.iiasa.ac.at/Publications/Documents/IR-10-003.pdf

IIASA (2010) GAINS - the greenhouse gas and air pollution interactions and synergies (GAINS)-model. Available at: http://gains.iiasa.ac.at/gains/EUR/index.login?logout=1

IPCC (2006) 2006 IPCC guidelines for national greenhouse gas inventories. In: Eggleston HS, Buendia L, Miwa K, Ngara T, Tanabe K (eds) Prepared by the National Greenhouse Gas Inventories Programme. Institute for Global Environmental Strategies, Japan

IPCC (1997) Revised 1996 IPCC guidelines for national greenhouse gas inventories, Vol. 1: Greenhouse gas inventory reporting instructions; Vol. 2: Greenhouse gas inventory workbook; Vol. 3: Greenhouse gas inventory reference manual. Intergovernmental Panel on Climate Change (IPCC) Working Group I (WG I) Technical Support Unit, IPCC/OECD/IEA, Bracknell, United Kingdom. Available at: http://www.ipccnggip.iges.or.jp/public/gl/invs1.htm

Jonas M, Gusti M, Jeda W, Nahorski Z, Nilsson S (2010a) Comparison of preparatory signal analysis techniques for consideration in the (post-)Kyoto policy process. Clim Chang 103:175-213 
Jonas M, Marland G, Winiwarter W et al (2010b) Benefits of dealing with uncertainty in greenhouse gas inventories: introduction. Clim Chang 103(1):3-18

Jonas M, Nilsson S, Bun R, Dachuk V, Gusti M, Horabik J, Jęda W, Nahorski Z (2004) Preparatory signal detection for Annex I countries under the Kyoto protocol - a lesson for the post-Kyoto policy process. Interim report IR-04-024, International Institute for Applied Systems Analysis, Laxenburg, Austria, p 91. Available at: http://www.iiasa.ac.at/Publications/Documents/IR-04-024.pdf

Lesiv M (2012) Influence of structural changes in emissions on total uncertainty. Interim report IR-12-018, International Institute for Applied Systems Analysis, Laxenburg, Austria, p 20

Lieberman D, Jonas M, Winiwarter W et al (2007) Accounting for climate change: introduction. Water Air Soil Pollut Focus 7:421-424

Marland G, Hamal K, Jonas M (2008) How uncertain are estimates of CO2 emissions? J Ind Ecol 13:4-7

National inventory reports (2003-2008) under the UNFCCC Treaty. Available at: http://unfccc.int/national reports/annex_i_ghg_inventories/national_inventories_submissions/items/4303.php

National Research Council (2010) Verifying greenhouse gas emissions: methods to support international climate agreements. National Academies Press, Washington. Available at: http://www.nap.edu/openbook.php? record id $=12883$ \&page $=11$

UNFCCC (2010) National inventory reports (2000-2008) under the UNFCCC treaty. Available at: http://unfecc. int/national_reports/annex_i_ghg_inventories/national_inventories_submissions/items/4303.php 